\title{
Epigenetic impairments in development of parthenogenetic preimplantation mouse embryos
}

\author{
Ngan Thi Kim $\mathrm{HO}^{1)^{*}}$, Thuy Van Thi NGUYEN ${ }^{1)^{*}}$, Thuan Van NGUYEN ${ }^{1)}$ and Hong-Thuy BUI ${ }^{1)}$ \\ ${ }^{1)}$ Cellular Reprogramming Laboratory, School of Biotechnology, International University, Vietnam National University, \\ Ho Chi Minh City 700000, Vietnam
}

\begin{abstract}
Parthenogenesis is an activation process of oocytes that occur without the participation of sperm. Evidence suggests that normal development of embryos requires proper expression of several imprinted genes inherited from both the paternal and maternal genomes. Compared to gene expression, histone modifications and chromatin remodeling are not well-documented. In this research, by using immunofluorescence staining for several developmental-associated histone modifications, we investigated whether epigenetic impairments in parthenogenetic embryos act as constraints for proper development. At early stages, fertilized embryos exhibited high methylation of histone H3 at lysine 9 (Me-H3-K9) and Heterochromatin Protein 1 (HP1) present in the maternal chromatin, while paternal chromatin showed weaker HP1 signals. We found that at the twocell stage in fertilized embryos, HP1, initially detected around the nucleolus, colocalized with chromocenters at one pole of the blastomere, while parthenotes showed a diffused distribution pattern of HP1 throughout the entire nucleoplasm. At the four-cell stage, methylation of histone $\mathrm{H} 3$ at arginine 26 (Me-H3-R26) increased at nascent RNA repression sites in fertilized embryos, while parthenotes recorded weaker signals throughout the nucleoplasm, suggesting differences in pluripotency of the ICM cells between the two types of embryos. Moreover, at the blastocyst stage, we observed that the acetylation level of histone H4 at lysine 12 (Ac-H4-K12) was significantly decreased in parthenogenetic ICM compared to that in its fertilized counterpart. To summarize, differences in epigenetic modifications correlating with paternal chromatin's capacity to regulate nascent RNA repression may contribute to aberrant development and lineage allocation in mouse parthenogenetic embryos.

Key words: Epigenetics, Histone acetylation, Histone methylation, Mouse parthenogenetic embryo, Nascent RNA production
\end{abstract}

(J. Reprod. Dev. 65: 83-90, 2019)

$\mathbf{P}$ arthenogenesis is a process in which zygotes are produced without sperm presence. Due to lack of paternal genes, parthenogenetic embryos cannot develop to full-term; however, these embryos show a great potential to generate histocompatible stem cells (parthenogenetic embryonic stem i.e. pES cells) for transplantation. Following fertilization, the paternal and maternal genomes undergo epigenetic changes and chromatin remodeling necessary to achieve transcriptional competence during early development [1]. In mice, the zygotic paternal genome is demethylated widely soon after fertilization, whereas the maternal genome remains highly methylated $[2,3]$. This asymmetric pattern of DNA methylation in the two parental genomes at the one-cell stage persists at least until the two-cell stage of the embryo [4], and is believed to be responsible for functional differences between the parental genomes during development. Chromatin remodeling is a multi-stage process with the newly fertilized oocyte in transition between gametic chromatin and embryonic chromatin which subsequently becomes transcriptionally

Received: March 1, 2018

Accepted: November 22, 2018

Published online in J-STAGE: December 29, 2018

(C)2019 by the Society for Reproduction and Development

Correspondence: H-T Bui (e-mail: bhthuy@hcmiu.edu.vn) and TV Nguyen (e-mail: nvthuan@hcmiu.edu.vn)

* NTK Ho and TVT Nguyen contributed equally to this work

This is an open-access article distributed under the terms of the Creative Commons Attribution Non-Commercial No Derivatives (by-nc-nd) License. (CC-BY-NC-ND 4.0: https://creativecommons.org/licenses/by-nc-nd/4.0/) competent. The result is that both male and female pronuclei are remodeled in the same environment producing "opposing" epigenetic outcomes $[5,6]$.

As a part of the "histone code", heterochromatin mediates many diverse functions in the cell nucleus, including centromere function, gene silencing, and nuclear organization [7]. The pericentromeric heterochromatin contains specific histone modifications, such as high level of methylation of histone $\mathrm{H} 3$ at lysine 9 (Me-H3-K9) and low level of acetylation of histone $\mathrm{H} 3$ at lysine 9 (Ac-H3-K9) or methylation of histone $\mathrm{H} 3$ at lysine 4 (Me-H3-K4) [8, 9]. MeH3-K9 creates a high-affinity binding site for Heterochromatin Protein 1 (HP1) [10], and HP1 proteins are thought to contribute to the transcriptional silencing of heterochromatin [8]. HP1 proteins might be recruited to pericentromeres by their binding to the newly deposited histone H3.3 that is methylated on lysine 9 prior to its deposition or becomes methylated after its incorporation into the chromatin $[8,11]$. On the other hand, chromocenters represent major heterochromatic domains and appear to be important for regulating proper centromere function. Chromocenters also play an important role in gene regulation and association of genes with chromocenters have been found to correlate with silencing in somatic cells [12]. It has been previously demonstrated that in mammalian embryos, both parental genomes display a peculiar distribution of pericentric heterochromatin and centromeres, organized around nucleolar precursor bodies (NPB) [12]. Chromocenter genesis is finally achieved by the end of the two-cell stage in mice [13]. Remarkably, these dynamics of epigenetic marks and reorganization of nuclear architecture appear 
closely connected to the functional state of the genome. Moreover, previous researches have demonstrated asymmetric distribution of HP1 and trimethylation of histone $\mathrm{H} 3$ at lysine 9 (Me-H3-K9) at one- and two-cell stage in fertilized embryos [14], but there are only a limited number of reports on HP1 formation and localization at these stages in parthenogenetic embryos.

Previously, we have discussed the importance of paternal chromatin in regulating zygotic gene activation (ZGA) [15]. In mouse fertilized embryos, ZGA was found to be repressed at the late two-cell stage, illustrated by a reduction in nascent RNA synthesis. In mouse parthenogenetic embryos, on the other hand, this phenomenon was postponed until the late four-cell stage [15]. Moreover, as early as the four-cell stage, fertilized embryos started to show their differentiation fate and cell potency. A report in 2007 showed that the four-cell blastomeres, which possessed higher methylation of histone $\mathrm{H} 3$ at arginine 26 (Me-H3-R26), directed their progeny to the ICM, and upregulation of this methylation led to a dramatic increase in Nanog and Sox 2 expression in mouse fertilized embryos [16]. However, Me-H3-R26 level during this stage has not been investigated in the case of parthenogenetic embryos.

In addition, acetylation of histone $\mathrm{H} 4$ at lysine 12 (Ac-H4-K12) was also proved to be closely related to gene transcription. Specifically, data have shown that some portions of sperm chromatin bear $\mathrm{H} 4$ lysine acetylations that are passed into the zygote and may be involved in early embryo development [17]. Furthermore, Ac-H4-K12 was enriched in the area surrounding the transcription start site (TSS), and the genes in that region showed a significant bias towards developmental functions; some of these genes were expressed at high levels in early zygotes [18]. Nevertheless, Ac-H4-K12 expression levels during preimplantation development of mouse parthenogenetic embryos have not been elucidated yet.

In this study, we investigated HP1 formation and localization, and Me-H3-R26 and Ac-H4-K12 expression during preimplantation development of parthenogenetic embryos and compared them to fertilized embryos. We found that these histone signatures were impaired in parthenotes and that paternal chromatin played a vital role in controlling these expressions.

\section{Materials and Methods}

\section{Mice and reagents}

Female ICR mice were used as oocyte donors throughout the experiment; all mice were about 8-10 weeks old. Animals were maintained in accordance with the guidelines of International University - Vietnam National University, Ho Chi Minh City. Chemicals were purchased from Sigma Chemical Co. (St. Louis, MO, USA) unless otherwise stated.

\section{Parthenogenesis}

Female ICR mice were super-ovulated by intraperitoneal injection of $5 \mathrm{IU}$ of equine chorionic gonadotropin (eCG), followed $48 \mathrm{~h}$ later by $5 \mathrm{IU}$ of human chorionic gonadotropin (hCG). Oocytes were then mechanically denuded from cumulus cells in Hepes modified CZB (Hepes-mCZB) medium containing hyaluronidase $(1 \mathrm{mg} / \mathrm{ml})$, then incubated in activation medium consisting of $\mathrm{Ca}^{2+}$-free $\mathrm{mCZB}$ medium supplemented with $10 \mathrm{mM} \mathrm{SrCl}_{2}$ and $5 \mu \mathrm{g} / \mathrm{ml}$ cytochalasin
$\mathrm{B}(\mathrm{CB})$ for $6 \mathrm{~h}$ at $37^{\circ} \mathrm{C}$ in a humidified atmosphere with $5 \% \mathrm{CO}_{2}$. After activation, oocytes containing two pronuclei $(2 \mathrm{PN})$ were selected and cultured in mCZB medium supplemented with $0.5 \%$ bovine serum albumin (BSA) during preimplantation development.

\section{Microinjection of spermatozoa}

For control studies, fertilized embryos were produced using intracytoplasmic sperm injection (ICSI) as described by Kimura and Yamanagichi [19] except that our experiment was performed at room temperature. Briefly, after washing, the sperm heads were separated from the tail by subjecting the head-tail junction to a few pulses using a piezo-activated micromanipulator system (Prime Tech, Aburaki, Tokyo, Japan). Only the sperm head was injected into each oocyte. After 10-20 min of recovery, ICSI embryos were cultured in $\mathrm{mCZB}$ medium supplemented with $0.5 \% \mathrm{BSA}$ at $37^{\circ} \mathrm{C}$ in humidified air with $5 \% \mathrm{CO}_{2}$ until the blastocyst stage.

\section{Incorporation of BrUTP into embryos and detection of new transcripts}

Each group of embryos $(<20)$ was washed twice in electrical permeabilization medium (EP: $0.25 \mathrm{M} \mathrm{D}$-glucose, $100 \mu \mathrm{M} \mathrm{CaCl}_{2} .2 \mathrm{H}_{2} \mathrm{O}$, $100 \mu \mathrm{M} \mathrm{MgSO}_{4}$, and $0.1 \%$ polyvinylpyrrolidone) and finally in one change of transcription buffer (EP + 10 mM BrUTP; Sigma Aldrich). They were then transferred into a chamber between electrodes overlaid with a $20 \mu \mathrm{l}$ droplet of transcription buffer. Two $80 \mu$ sec electric pulses at $250 \mathrm{~V} / \mathrm{cm}$ of direct current were triggered using an Electro Cell Fusion apparatus (Bex LF101L, Tokyo, Japan) with a 2 min interval between pulses. Two minutes after permeabilization, embryos were cultured in mCZB medium for $1 \mathrm{~h}$ further under the same conditions as above. The embryos were then fixed in $4 \%$ paraformaldehyde and new transcripts incorporating BrUTP were visualized by indirect immunofluorescence [15].

\section{Immunofluorescence microscopy}

Embryos were fixed in 4\% Paraformaldehyde and treated as described previously [20]. The primary antibodies used were rabbit polyclonal anti-histone H4 at lysine 12 (Ac-H4-K12; Upstate Cell Signaling Solutions, Charlottesville, VA, USA), rabbit antitrimethyl-histone $\mathrm{H} 3$ at lysine 9 (Me-H3-K9; Abcam, Cambridge, UK), mouse monoclonal anti-CREST (Santa Cruz Biotechnology, Europe), goat polyclonal anti-HP1 $\beta$ (Santa Cruz Biotechnology, Europe), rabbit polyclonal anti-dimethyl-histone $\mathrm{H} 3$ at arginine 26 (Me-H3-R26, Abcam, Cambridge, UK), mouse anti-histone H3 at lysine 9 (Ac-H3-K9; Upstate Cell Signaling Solutions, Charlottesville, VA, USA), and mouse monoclonal anti-BrdU (Roche Diagnostics, Germany). The secondary antibodies were Alexa-Fluor-568-labeled goat anti-mouse IgG or Alexa-Fluor-568-labeled donkey anti-goat IgG or Alexa-Fluor-488-labeled chicken anti-rabbit IgG antibodies (Molecular Probes, Eugene, OR, USA). DNA was counterstained with $2 \mu \mathrm{g} / \mathrm{ml}$ 4,6-diamidino-2-phenylindole (DAPI; Molecular Probes).

\section{Quantitation of fluorescence intensity in nuclei}

Embryos were observed using a fluorescence microscope (Olympus Optical, Tokyo, Japan). Fluorescence intensities of nuclei were measured by manually outlining all nuclei in the display as described previously [21]. Briefly, nuclei were selected randomly. The total 
intensity in each nucleus was measured from five different regions and the background value for the cytoplasm was subtracted. This calculated intensity was multiplied by the nuclear volume to estimate the total amount of fluorescence for the nucleus. One-cell embryos were measured at 10,12 , and $14 \mathrm{~h}$ after sperm injection or activation and intensity was calculated based on a mean of two pronuclei. For two-cell, late two-cell, four-cell, late four-cell and eight-cell, and morula/blastocyst stages, embryos were measured at 24, 32, 48, 54, 62 , and $84 \mathrm{~h}$ after sperm injection or activation, respectively [15].

\section{Statistical analysis}

Student's $t$-test was used to estimate the significance of any differences between experimental groups in immunofluorescence studies. Each experiment was repeated at least three times and about 60 immunostained oocytes were examined in each group. The data were subjected to arcsine transformation for each replication to normalize them. The transformed values were analyzed by one-way ANOVA using Microsoft ${ }^{\circledR}$ Excel (Microsoft ${ }^{\circledR}$ Software by Microsoft Corporation) and significance level was considered at $\mathrm{P}<0.05$.

\section{Results}

\section{Me-H3-K9 and HP1 are asymmetrically distributed in maternal and paternal genomes of fertilized embryos}

One of the reasons that arrests parthenogenetic embryo development at E9.5 is the lack of paternal genes. Our previous results have shown that male-derived factors play a key role in the regulation of transcription repression in the two-cell to four-cell transition through differences between male and female chromatin remodeling, DNA synthesis, and nascent RNA production [15]. In order to clarify the role of paternal chromatin in this phenomenon, we first examined acetylation of histone $\mathrm{H} 3$ at lysine 9 (Ac-H3-K9), methylation of histone $\mathrm{H} 3$ at lysine 9 (Me-H3-K9) and Heterochromatin Protein 1 (HP1) allocation in early fertilized embryos. Soon after fertilization, maternal chromatin showed high level of HP1 expression while this signal was not expressed in paternal chromatin (Fig. 1A-k). After 3 $\mathrm{h}$ of fertilization, a weak signal of HP1 started to appear in paternal chromatin while HP1 signal was still maintained at a high level in the maternal chromatin (Fig. 1A-1). Although both pronuclei expressed Ac-H3-K9, they showed an asymmetric methylation of H3-K9 between maternal and paternal chromatin in the 1-cell stage (Fig. 1B-c). It is suggested that in mouse early embryos, pericentromeric heterochromatin $(\mathrm{PCH})$ contains Suv39h/HP1 in a parental-specific manner. The targeting mechanism present in the paternal $\mathrm{PCH}$ is absent in the maternal PCH due to the presence of the Suv39h/HP1 pathway; therefore, H3K9me3-independent accumulation of HP1 occurs in the paternal pronuclei [11]. These results indicate the role of paternal chromatin in regulating epigenetic asymmetries between two pronuclei of mouse embryos in the first cell cycle.

Centromere relocation at the chromocenter of nucleoplasm was delayed in parthenogenetic embryos compared to fertilized embryos

In the next step, we focused more on the formation of chromocenters during the first two cell cycles. These structures are involved in centromere function and regulation of gene transcription [22, 23].
HP1 is associated with heterochromatin and is usually enriched in chromocenters [22]. Localization of kinetochores and pericentric chromatin were detected using anti-CREST antibody.

At the 1-cell stage, HP1 was present in the nucleoplasm and presented a perinucleolar ring around the NPB, colocalizing with DNA in the female pronuclei while in the male pronuclei, HP1 signal was dimmer and homogeneously distributed in the nucleoplasm until $4 \mathrm{~h}$ after fertilization (Fig. 1A-n). There was accumulation of HP1 around the NPB in male pronuclei concomitant with the pericentric heterochromatin forming a ring around the NPB after $6 \mathrm{~h}$ of fertilization (Fig. 2A-b). In fertilized embryo, at the early two-cell stage, pericentric DNA became localized at one pole of nucleus, and centromeres accumulated around the nucleolus (Fig. 2B-a, 2B-b). In the late 2-cell stage, kinetochores were polarized and compacted at the chromocenters at one pole of the nucleus (Fig. 2B-c, 2B-d). In parthenogenetic embryos, at the early 2 -cell stage, centromeres were grouped around the nucleolus (Fig. 2B-e, 2B-f); however, at the late 2 -cell stage, the positions of kinetochores and chromocenters were still diffused throughout the nucleoplasm (Fig. 2B-g, 2B-h), and the kinetochores were colocalized with the compacted chromocenters at the 4-cell stage (data not shown). This indicates that relocation of the centromeres at the chromocenter of nucleoplasm was delayed in parthenogenetic embryos.

Methylation of histone $\mathrm{H} 3$ at Arginine 26 express a diffused distribution pattern in four-cell stage parthenogenetic embryos

Recent findings have demonstrated that cells in mouse embryos can differ in their developmental fate and potency at the four-cell stage [24]. Since epigenetics is suggested to be involved in maintaining pluripotency, we inspected the expression of methylation of histone $\mathrm{H} 3$ at arginine 26 (Me-H3-R26) at the two- and four-cell stage in parthenogenetic embryos. This methylation is one of the most common posttranslational modifications; it promotes DNA accessibility and biases cells to their ICM fate [16].

At the two-cell stage, nascent RNA distribution was found to be uniform throughout the nuclei corresponding with high levels of Me-H3-R26 expression in both fertilized and parthenogenetic embryos (Fig. 3A-b, 3A-f, 3A-c, 3A-g). We have reported previously that the two-cell to four-cell transition resulted in a repression of nascent RNA production in some regions of the nuclei in fertilized but not in parthenogenetic embryos [15]. In this study, a closer look at the early four-cell blastomere from both types of embryos revealed high levels of Me-H3-R26 compacted in which nascent RNA was repressed in fertilized embryos (Fig. 3B-b, 3B-c). In contrast, the methylation level of H3-R26 seemed to be weaker and diffused throughout the nucleoplasm concomitant with uniform distribution of nascent RNA in parthenogenetic embryos (Fig. 3B-f, 3B-g). We found that H3-R26 was methylated higher in fertilized than in parthenogenetic embryos at the four-cell stage. This may lead to the higher levels of methylation of H3-R26 observed in the ICM of fertilized blastocysts as compared to parthenogenetic blastocysts (Fig. 3C).

Acetylation level of histone $\mathrm{H} 4$ at lysine 12 was lower in ICM of parthenogenetic than that in fertilized blastocysts

In the next step, we investigated another paternal chromatin contribution by examining acetylation of histone $\mathrm{H} 4$ at lysine 12 


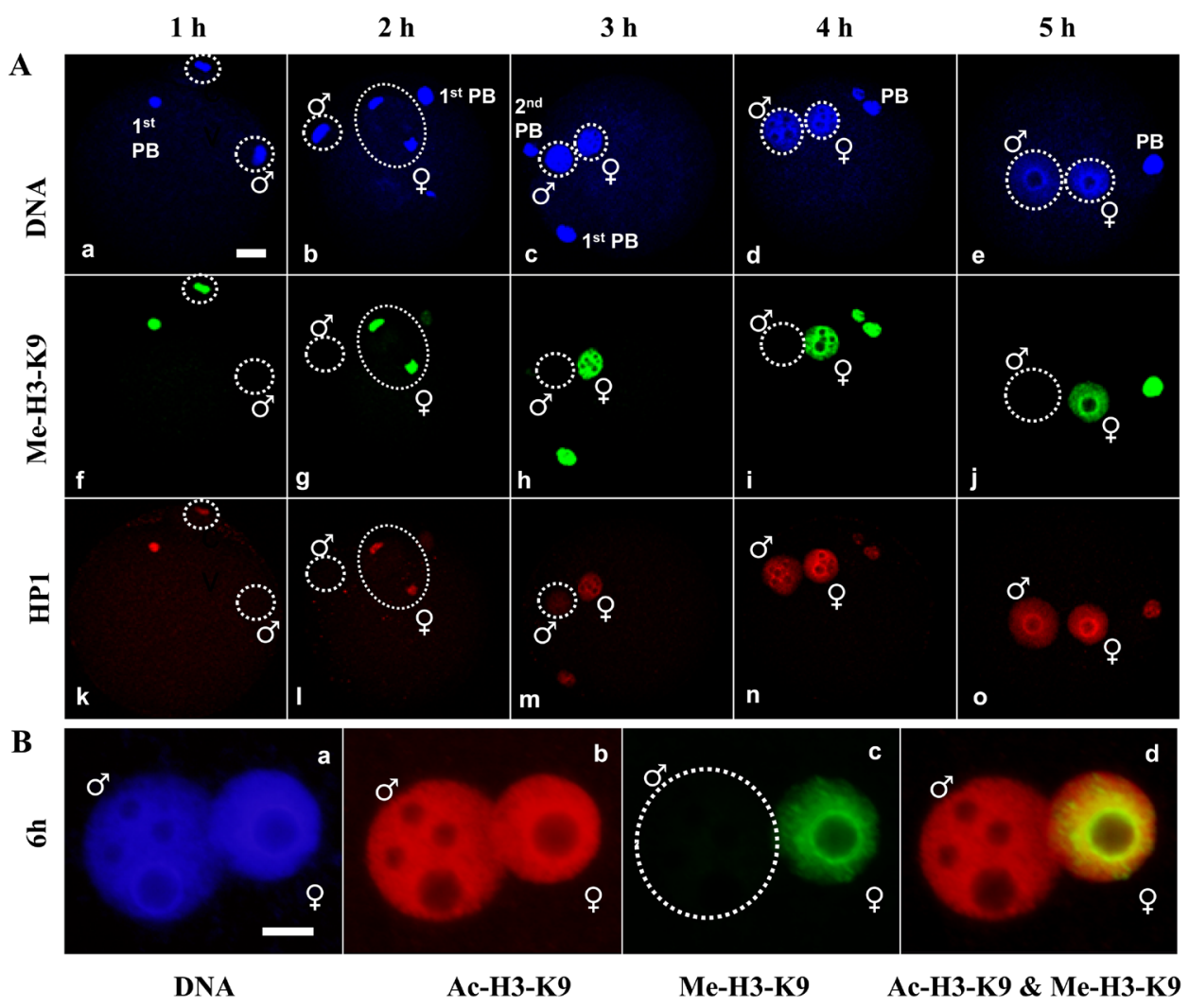

Fig. 1. Histone H3 modifications and Heterochromatin Protein 1 formation in one-cell embryo after fertilization. (A) Expression of methylation of histone $\mathrm{H} 3$ at lysine $9(\mathrm{Me}-\mathrm{H} 3-\mathrm{K} 9)(\mathrm{f}-\mathrm{j})$ and $\mathrm{HP} 1 \mathrm{k}-\mathrm{o})$ in paternal and maternal chromatin $5 \mathrm{~h}$ after fertilization. Maternal chromatin shows high expression level of Me-H3-K9, while paternal chromatin showed hypomethylation. Soon after fertilization, maternal chromatin showed high level of HP1 expression while this signal was not expressed in paternal chromatin. (B) Acetylation of histone H3 at lysine 9 (Ac-H3-K9) and Me$\mathrm{H} 3-\mathrm{K} 9$ in 1-cell embryo at $6 \mathrm{~h}$ after fertilization. Although both pronuclei show Ac-H3-K9 (b); they showed an asymmetric methylation of H3-K9 between maternal and paternal chromatin in the 1-cell stage (c). The DNA was counterstained with DAPI. Bar $=10 \mu \mathrm{m}$.

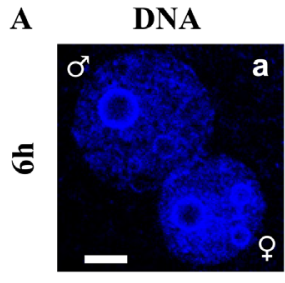

HP1

CREST HP1 \& CREST

B HP1 \& CREST

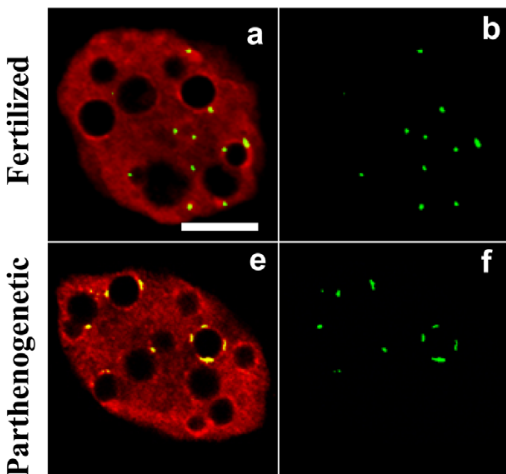

Early 2-cell embryos (20h)
HP1 \& CREST CREST

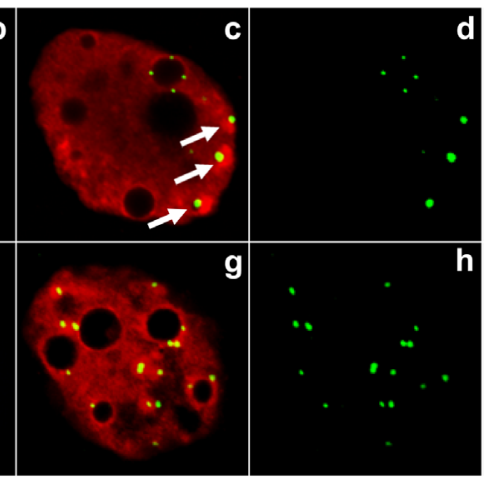

Late 2-cell embryos (36h)
Fig. 2. Distribution of Heterochromatin Protein 1 (HP1) and kinetochores in one-cell and two-cell embryos. (A) There was accumulation of HP1 around the NPB in male pronuclei concomitant with the pericentric heterochromatin ring around the NPB at 1-cell stage, $6 \mathrm{~h}$ after fertilization. (B) At the early two-cell stage, centromeres aggregated around the nucleolus in both types of embryos (a, b, e, f). At the late two-cell embryos, kinetochores were polarized and compacted at the chromocenters at one pole of the nucleus in fertilized embryos (c, d; Arrows). However, the position of kinetochores and chromocenters were diffused throughout the nucleoplasm in parthenotes $(\mathrm{g}, \mathrm{h})$. The DNA was counterstained with DAPI. Bar $=10 \mu \mathrm{m}$. 

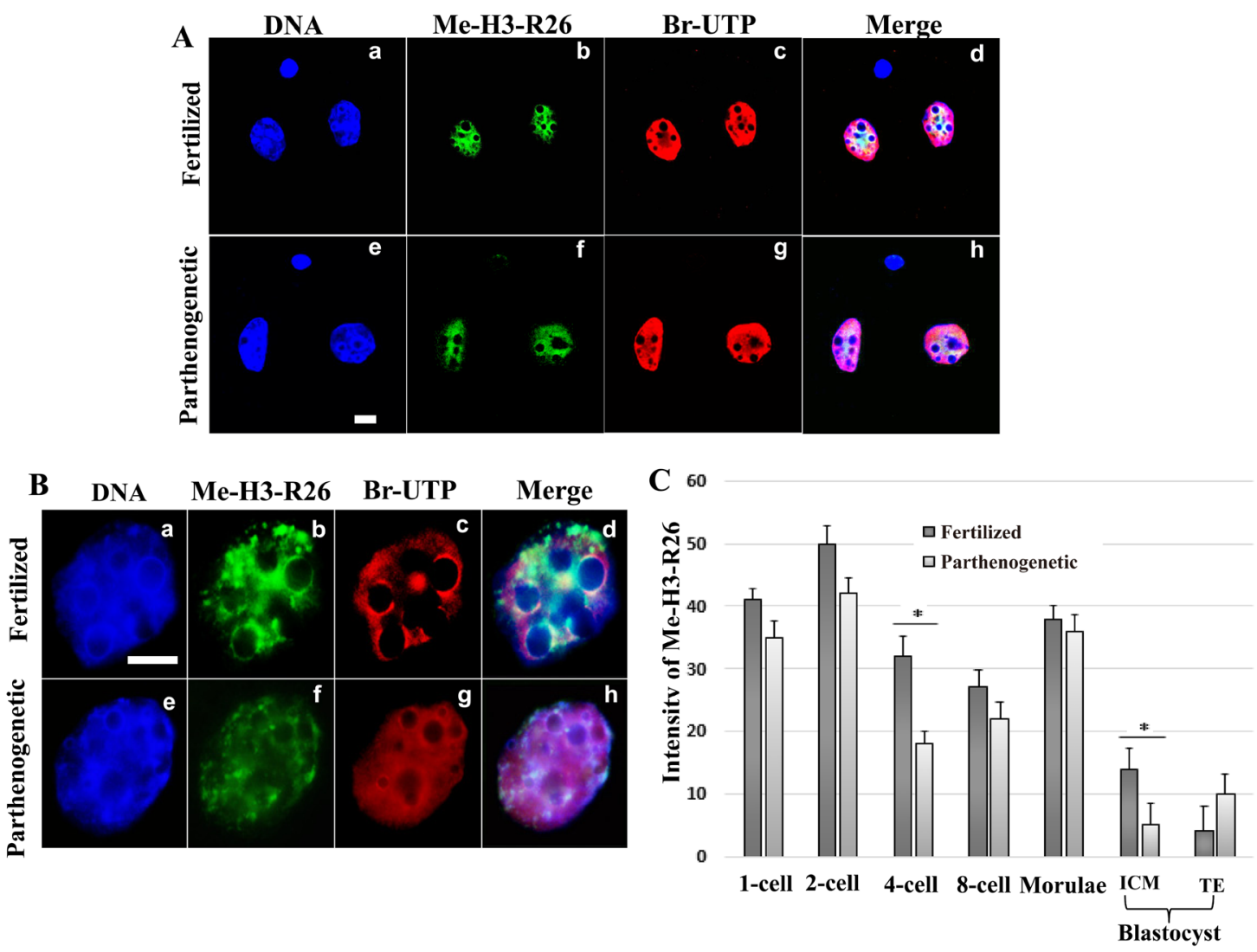

Fig. 3. Expression of methylation of histone $\mathrm{H} 3$ at arginine 26 (Me-H3-R26) and nascent RNA at two- and four-cell stages in fertilized and parthenogenetic embryos. Embryos were subjected to electrical permeabilization in the presence of BrUTP, cultured for $1 \mathrm{~h}$ and collected for the detection of BrUTP-labeled RNA transcripts and Me-H3-R26 by immunostaining. (A) At the two-cell stage, nascent RNA distribution was uniform throughout the nuclei, corresponding with high levels of Me-H3-R26 expression in both fertilized and parthenogenetic embryos. (B) High levels of Me-H3-R26 were compacted in which nascent RNA was repressed in fertilized embryos (b and c). In contrast, methylation level of H3-R26 seemed to be weaker and diffused throughout the nucleoplasm concomitant with uniform distribution of nascent RNA in parthenogenetic embryos. (C) Intensity of MeH3-R26 expression during preimplantation development of fertilized and parthenogenetic embryos. Expression levels were significantly different (asterisks) at the 4-cell stage and in ICM cells of fertilized and parthenogenetic embryos. The DNA was counterstained with DAPI. Bar $=10 \mu \mathrm{m}$.

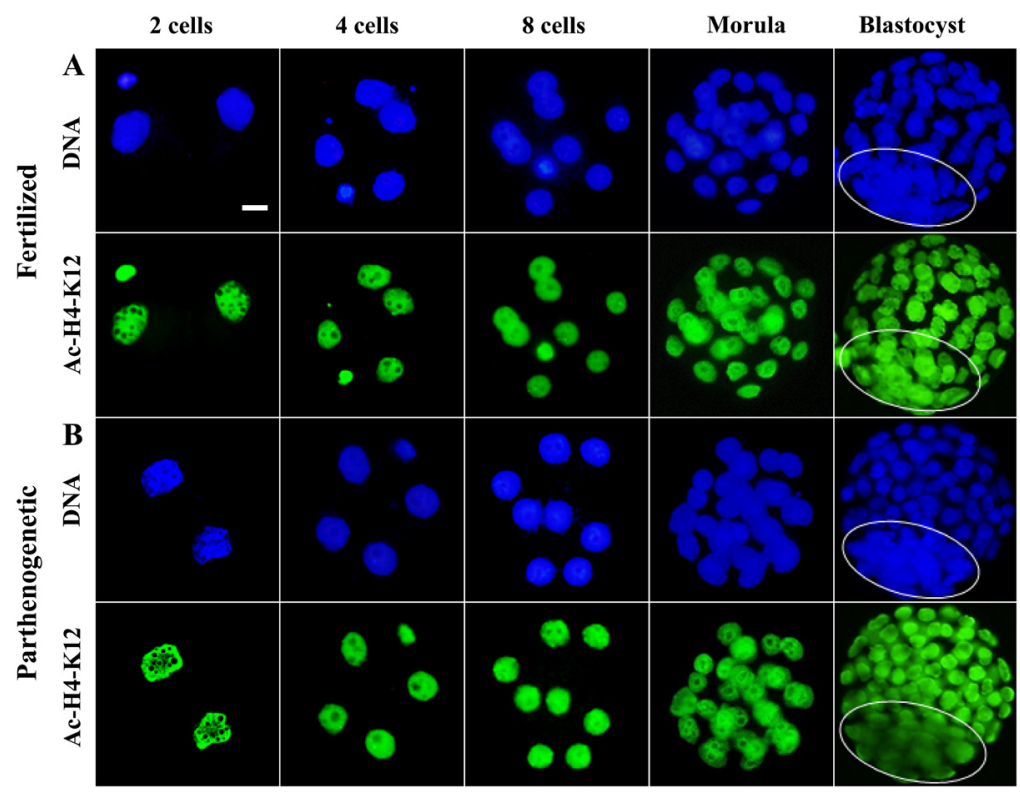

Fig. 4. Expression of histone $\mathrm{H} 4$ acetylation at lysine 12 (Ac-H4-K12) in fertilized (A) and parthenogenetic (B) embryos during preimplantation development. Acetylation level of H4-K12 was maintained at a high level in both fertilized and parthenogenetic embryos in the two-cell, four-cell, eight-cell, and morula stage. At the blastocyst stage, acetylation level of H4-K12 was lower in ICM of parthenogenetic compared to that in fertilized embryos. The circles in blastocysts indicate their ICM. Bar $=10 \mu \mathrm{m}$. 
(Ac-H4-K12) from the one-cell to blastocyst stage in parthenogenetic embryos. This common histone acetylation has been known to be involved in zygotic gene transcription and exhibited a close relationship with the expression of pluripotent genes, such as Oct4 and Nanog [25].

Our previous results demonstrated that in the case of fertilized embryos, at the one-cell stage, the acetylation level of H4-K12 was higher in expanded paternal pronucleus, and weaker in maternal pronucleus [15]. In this study, we found that H4-K12 was highly acetylated in both fertilized and parthenogenetic embryos from the two-cell to morula stage. However, at the blastocyst stage, the acetylation level of H4-K12 was lower in ICM of parthenogenetic blastocysts as opposed to that in fertilized embryos (Fig. 4). Such unusual levels of acetylation may induce a downregulation in expression of important pluripotent genes, contributing to developmental defects in parthenotes.

\section{Discussion}

The presence of both parental chromatin enables the establishment of asymmetric epigenetics in the zygote, which is essential for proper nuclear reprograming and restoration of cell totipotency during preimplantation development [26]. The absence of one parental genome can lead to aberrant expression of imprinted, developmental and pluripotent genes, triggering changes in cell potency $[4,14]$. In this study, we have investigated some important histone modifications in fertilized and parthenogenetic embryos, then demonstrated the role of paternal chromatin in controlling these epigenetic expressions. Soon after fertilization, transcriptional activity was immediately associated with paternal chromatin, and this induced transcription was also higher in the male pronucleus [27]. Various epigenetic modifications are known to be involved in the reprogramming of the parental genome $[28,29]$. The first observation of nucleosomal histones, including acetylation and methylation, is important for regulating gene transcription and silencing [30,31]. Modifications can occur at several amino acid residues, in which lysine 9 of histone H3 is a notable example, which can be acetylated or methylated [32]. We demonstrated that soon after ICSI, the paternal pronucleus expanded quickly and showed a high level of acetylation of H4-K12, whereas the maternal pronucleus was smaller, with weak staining for acetylation, in addition, at the two-cell stage, male chromatin and female chromatin contributed separately to show different patterns of histone methylation [15]. This combination of the male and female chromatin might induce a rapid decrease in nascent RNA production during the two-cell to four-cell transition in fertilized embryos.

$\mathrm{HP}$ 1, a heterochromatin that interacts with Me-H3-K9, is a component of silent chromatin at telomeres and centrosomes. The time-lapse observation revealed that the chromatin association of HP1beta is regulated in a cell cycle-dependent manner [33]. As a reflection of chromatin organization, HP1 signals started to appear in paternal pronucleus at $4 \mathrm{~h}$ after fertilization. It was located around the nucleolus of pronuclei, and was higher in maternal chromatin, reconfirming exclusive expression of methylation in female pronucleus. Moreover, heterochromatin is also implicated in other basic cellular functions, including repression of inadequate transcription [34], cohesion of kinetochores [35], and stability of chromosomes
[36]. Previous results have suggested the existence of a stage-specific nuclear organization that was reminiscent of mouse antral oocytes [37]. Specifically, prior to ovulation, the kinetochores and pericentric heterochromatin of mouse pre-ovulatory oocytes cluster around the nucleolus and gene transcription is shut down [38]. Transcription can first be detected at the end of the first cell cycle [39]. Thus, the nuclear organization in one-cell embryos can provide a necessary constraint for further development. At the two-cell stage, Rabl-like configuration is typical for the nuclear organization, in which polarized arrangement of kinetochores resembles a half-moon [14]. This was in accordance with the distribution previously described in two-cell stage mouse embryos by Mayer's group [40] and Martin's group [12]. The polarity in a Rabl-like configuration as well as the large numbers of chromocenters may imply some constraints on nuclear restructure implying regulations of gene expression. In addition, the presence of this configuration may correlate in time with the major wave of genome activation; however, whether there is a causal connection between the two is still unknown. It has been demonstrated that in fertilized embryos, nascent RNA production was repressed at the late two-cell stage, but not in the case of parthenogenetic embryos, in which this phenomenon was maintained until late four-cell stage [15]. At the late two-cell stage, fertilized embryos exhibited chromocenters associated with HP1 and polarized in one pole of the blastomere. On the other hand, not all chromocenters in parthenogenetic embryos were linked with HP1, and high number of chromocenters were still diffused throughout the nucleoplasm, confirming a delay in nascent RNA repression in parthenogenetic blastocysts. Lack of the paternal genome might contribute to this abnormality, and this may be one of the reasons affecting parthenotes' later development. At this stage, zygotic genes should be silenced so that the embryonic genes can be expressed to sustain proper development of the embryos [27], and it appears that paternal genome might be involved in activation of the embryonic genome.

The evidence provided in this study has demonstrated that non-uniform epigenetics between blastomeres imposes heritable instructions for lineage-specific differentiation [26, 28]. Among common histone modifications, methylation of histone $\mathrm{H} 3$ at arginine 26 in blastomeres, at the four-cell stage, was proved to significantly display lineage allocation and cell fate determination [16, 24]. In fertilized embryos, since nascent RNA expression had already been repressed at the late two-cell stage; as a result, at the early four-cell stage, upregulation of Me-H3-R26 expression indicated the onset of embryonic genes. High signals of Me-H3-R26 were concentrated at the location where nascent RNA was repressed. On the other hand, parthenogenetic four-cell blastomere showed weaker and uniform expression of Me-H3-R26 throughout the nucleoplasm. The reason for this phenomenon may be because nascent RNA repression does not occur at this stage in the parthenogenetic blastocyst. Due to the balance in the level of gene expression, differentiated genes could not be expressed in the parthenogenetic blastocyst. Moreover, in 2015, Chen and Yu's group [41] proposed decreased Nanog and Sox 2 expression in parthenotes in the blastocyst stage, given that these gene expressions were upregulated by CARM1-mediated Me-H3-R26 [16, 42]. As a result, low levels of Me-H3-R26 at the four-cell stage might lead to lower number of cells directing their progeny to the ICM, and decreased expression of Me-H3-R26 in 
parthenogenetic ICM cells. Consequently, aberrant pluripotency in the ICM cells might directly affect pES establishment rate and differentiation capacity.

In addition, previous studies have suggested that changes in chromatin structure underlie, at least in part, zygotic gene activation in the mouse [43]. Specifically, histone $\mathrm{H} 4$ acetylation is incorporated with chromatin remodeling during differentiation and development. It has been suggested that this acetylated region preferentially initiates transcription in the mouse embryos at the one- and two-cell stage. At later stages, chromatin formation bearing these acetylated histone $\mathrm{H} 4$ may be required for countering a transcriptionally repressive state that follows the first mitosis [44-46]; hence, sustaining continued gene expression for normal development of the embryos [43]. Recently, Ac-H4-K12 has been found to be important in paternal influence on early gene expression in the zygote [17]. We observed homogenous expression of Ac-H4-K12 in all the blastomeres of both parthenogenetic and fertilized embryos from the two-cell to the morula stage. At the blastocyst stage, ICM cells of parthenogenetic embryos expressed significantly lower levels of Ac-H4-K12 than that of fertilized ones, indicating impairments of gene expression in the parthenogenetic ICM cells. Because Ac-H4-K12 was required for the recruitment of the transcription factor Oct4 to its binding site in the Nanog promoter [25]; therefore, the reduction of Ac-H4-K12 may be one of the reasons contributing to reduced Nanog and Oct4 expression in parthenogenetic ICM cells. This might have an impact on $\mathrm{pES}$ cell maintenance and differentiation, and we will study these aspects in future studies. In conclusion, differences in epigenetic modifications correlating to paternal chromatin's capacity to regulate nascent RNA repression may contribute to the aberrant development and lineage allocation in mouse parthenogenetic embryos.

Conflicts of interest: The authors declare no conflicts of interest in the research.

\section{Acknowledgements}

This research is funded by Vietnam National Foundation for Science and Technology Development (NAFOSTED) under Grant number "106-NN.99-2015.90; by Vietnam Ministry of Science and Technology under Grant No. ĐTĐL.CN-49/16; by Vietnam National University Ho Chi Minh City (VNU-HCM) under Grant No. B2016-28-01 and B2017-28-04.

\section{References}

1. Jenkins TG, Carrell DT. Dynamic alterations in the paternal epigenetic landscape following fertilization. Front Genet 2012; 3: 143. [Medline] [CrossRef]

2. Mayer W, Niveleau A, Walter J, Fundele R, Haaf T. Demethylation of the zygotic paternal genome. Nature 2000; 403: 501-502. [Medline] [CrossRef]

3. Young LE, Beaujean N. DNA methylation in the preimplantation embryo: the differing stories of the mouse and sheep. Anim Reprod Sci 2004; 82-83: 61-78. [Medline] [CrossRef]

4. Barton SC, Arney KL, Shi W, Niveleau A, Fundele R, Surani MA, Haaf T. Genomewide methylation patterns in normal and uniparental early mouse embryos. Hum $\mathrm{Mol}$ Genet 2001; 10: 2983-2987. [Medline] [CrossRef]

5. Santos F, Peters AH, Otte AP, Reik W, Dean W. Dynamic chromatin modifications characterise the first cell cycle in mouse embryos. Dev Biol 2005; 280: 225-236. [Medline] [CrossRef]

6. Canovas S, Ross PJ. Epigenetics in preimplantation mammalian development. Therio- genology 2016; 86: 69-79. [Medline] [CrossRef]

7. Dillon N, Festenstein R. Unravelling heterochromatin: competition between positive and negative factors regulates accessibility. Trends Genet 2002; 18: 252-258. [Medline] [CrossRef]

8. Zhang R, Liu ST, Chen W, Bonner M, Pehrson J, Yen TJ, Adams PD. HP1 proteins are essential for a dynamic nuclear response that rescues the function of perturbed heterochromatin in primary human cells. Mol Cell Biol 2007; 27: 949-962. [Medline] [CrossRef]

9. Saksouk N, Simboeck E, Déjardin J. Constitutive heterochromatin formation and transcription in mammals. Epigenetics Chromatin 2015; 8: 3. [Medline] [CrossRef]

10. Zeng W, Ball AR Jr, Yokomori K. HP1: heterochromatin binding proteins working the genome. Epigenetics 2010; 5: 287-292. [Medline] [CrossRef]

11. Tardat M, Albert M, Kunzmann R, Liu Z, Kaustov L, Thierry R, Duan S, Brykczynska U, Arrowsmith CH, Peters AH. Cbx2 targets PRC1 to constitutive heterochromatin in mouse zygotes in a parent-of-origin-dependent manner. Mol Cell 2015; 58: 157-171. [Medline] [CrossRef]

12. Martin C, Beaujean N, Brochard V, Audouard C, Zink D, Debey P. Genome restructuring in mouse embryos during reprogramming and early development. Dev Biol 2006; 292: 317-332. [Medline] [CrossRef]

13. Pichugin A, Le Bourhis D, Adenot P, Lehmann G, Audouard C, Renard JP, Vignon $\mathbf{X}$, Beaujean N. Dynamics of constitutive heterochromatin: two contrasted kinetics of genome restructuring in early cloned bovine embryos. Reproduction 2010; 139: 129-137. [Medline] [CrossRef]

14. Merico V, Barbieri J, Zuccotti M, Joffe B, Cremer T, Redi CA, Solovei I, Garagna S. Epigenomic differentiation in mouse preimplantation nuclei of biparental, parthenote and cloned embryos. Chromosome Res 2007; 15: 341-360. [Medline]

15. Bui HT, Wakayama S, Mizutani E, Park KK, Kim JH, Van Thuan N, Wakayama T. Essential role of paternal chromatin in the regulation of transcriptional activity during mouse preimplantation development. Reproduction 2011; 141: 67-77. [Medline] [CrossRef]

16. Torres-Padilla ME, Parfitt DE, Kouzarides T, Zernicka-Goetz M. Histone arginine methylation regulates pluripotency in the early mouse embryo. Nature 2007; 445: 214-218. [Medline] [CrossRef]

17. van der Heijden GW, Derijck AA, Ramos L, Giele M, van der Vlag J, de Boer P. Transmission of modified nucleosomes from the mouse male germline to the zygote and subsequent remodeling of paternal chromatin. Dev Biol 2006; 298: 458-469. [Medline] [CrossRef]

18. Paradowska AS, Miller D, Spiess AN, Vieweg M, Cerna M, Dvorakova-Hortova K, Bartkuhn M, Schuppe HC, Weidner W, Steger K. Genome wide identification of promoter binding sites for $\mathrm{H} 4 \mathrm{~K} 12 \mathrm{ac}$ in human sperm and its relevance for early embryonic development. Epigenetics 2012; 7: 1057-1070. [Medline] [CrossRef]

19. Kimura Y, Yanagimachi R. Intracytoplasmic sperm injection in the mouse. Biol Reprod 1995; 52: 709-720. [Medline] [CrossRef]

20. Bui HT, Yamaoka E, Miyano T. Involvement of histone H3 (Ser10) phosphorylation in chromosome condensation without $\mathrm{Cdc} 2$ kinase and mitogen-activated protein kinase activation in pig oocytes. Biol Reprod 2004; 70: 1843-1851. [Medline] [CrossRef]

21. Bui HT, Wakayama S, Kishigami S, Kim JH, Van Thuan N, Wakayama T. The cytoplasm of mouse germinal vesicle stage oocytes can enhance somatic cell nuclear reprogramming. Development 2008; 135: 3935-3945. [Medline] [CrossRef]

22. Guenatri M, Bailly D, Maison C, Almouzni G. Mouse centric and pericentric satellite repeats form distinct functional heterochromatin. J Cell Biol 2004; 166: 493-505. [Medline] [CrossRef]

23. Müller S, Almouzni G. Chromatin dynamics during the cell cycle at centromeres. Nat Rev Genet 2017; 18: 192-208. [Medline] [CrossRef]

24. Goolam M, Scialdone A, Graham SJL, Macaulay IC, Jedrusik A, Hupalowska A, Voet T, Marioni JC, Zernicka-Goetz M. Heterogeneity in Oct4 and Sox2 targets biases cell fate in 4-cell mouse embryos. Cell 2016; 165: 61-74. [Medline] [CrossRef]

25. Kim MS, Cho HI, Park SH, Kim JH, Chai YG, Jang YK. The histone acetyltransferase Myst2 regulates Nanog expression, and is involved in maintaining pluripotency and selfrenewal of embryonic stem cells. FEBS Lett 2015; 589: 941-950. [Medline] [CrossRef]

26. Morgan HD, Santos F, Green K, Dean W, Reik W. Epigenetic reprogramming in mammals. Hum Mol Genet 2005; 14: R47-R58. [Medline] [CrossRef]

27. Aoki F, Worrad DM, Schultz RM. Regulation of transcriptional activity during the first and second cell cycles in the preimplantation mouse embryo. Dev Biol 1997; 181: 296-307. [Medline] [CrossRef]

28. Reik W. Stability and flexibility of epigenetic gene regulation in mammalian development. Nature 2007; 447: 425-432. [Medline] [CrossRef]

29. Li E. Chromatin modification and epigenetic reprogramming in mammalian development Nat Rev Genet 2002; 3: 662-673. [Medline] [CrossRef]

30. Kouzarides T. Chromatin modifications and their function. Cell 2007; 128: 693-705. [Medline] [CrossRef]

31. Xu Y-N, Cui X-S, Tae J-C, Jin Y-X, Kim N-H. DNA synthesis and epigenetic modifi- 
cation during mouse oocyte fertilization by human or hamster sperm injection. $J$ Assist Reprod Genet 2011; 28: 325-333. [Medline] [CrossRef]

32. Jenuwein T, Allis CD. Translating the histone code. Science 2001; 293: 1074-1080. [Medline] [CrossRef]

33. Yamazaki T, Kobayakawa S, Yamagata K, Abe K, Baba T. Molecular dynamics of heterochromatin protein 1 beta, HPlbeta, during mouse preimplantation development. $J$ Reprod Dev 2007; 53: 1035-1041. [Medline] [CrossRef]

34. Lehnertz B, Ueda Y, Derijck AA, Braunschweig U, Perez-Burgos L, Kubicek S, Chen T, Li E, Jenuwein T, Peters AH. Suv39h-mediated histone H3 lysine 9 methylation directs DNA methylation to major satellite repeats at pericentric heterochromatin. Curr Biol 2003; 13: 1192-1200. [Medline] [CrossRef]

35. Bernard P, Maure JF, Partridge JF, Genier S, Javerzat JP, Allshire RC. Requirement of heterochromatin for cohesion at centromeres. Science 2001; 294: 2539-2542. [Medline] [CrossRef]

36. Peters AH, O'Carroll D, Scherthan H, Mechtler K, Sauer S, Schöfer C, Weipoltshammer K, Pagani M, Lachner M, Kohlmaier A, Opravil S, Doyle M, Sibilia M, Jenuwein T. Loss of the Suv39h histone methyltransferases impairs mammalian heterochromatin and genome stability. Cell 2001; 107: 323-337. [Medline] [CrossRef]

37. Longo F, Garagna S, Merico V, Orlandini G, Gatti R, Scandroglio R, Redi CA, Zuccotti M. Nuclear localization of NORs and centromeres in mouse oocytes during folliculogenesis. Mol Reprod Dev 2003; 66: 279-290. [Medline] [CrossRef]

38. Christians E, Boiani M, Garagna S, Dessy C, Redi CA, Renard JP, Zuccotti M. Gene expression and chromatin organization during mouse oocyte growth. Dev Biol 1999; 207:
76-85. [Medline] [CrossRef]

39. Bouniol C, Nguyen E, Debey P. Endogenous transcription occurs at the 1-cell stage in the mouse embryo. Exp Cell Res 1995; 218: 57-62. [Medline] [CrossRef]

40. Mayer W, Smith A, Fundele R, Haaf T. Spatial separation of parental genomes in preimplantation mouse embryos. J Cell Biol 2000; 148: 629-634. [Medline] [CrossRef]

41. Chen Y-H, Yu J. Epigenetic disruptions of histone signatures for the trophectoderm and inner cell mass in mouse parthenogenetic embryos. Stem Cells Dev 2015; 24: 550-564. [Medline] [CrossRef]

42. Wu Q, Bruce AW, Jedrusik A, Ellis PD, Andrews RM, Langford CF, Glover DM, Zernicka-Goetz M. CARM1 is required in embryonic stem cells to maintain pluripotency and resist differentiation. Stem Cells 2009; 27: 2637-2645. [Medline] [CrossRef]

43. Worrad DM, Turner BM, Schultz RM. Temporally restricted spatial localization of acetylated isoforms of histone $\mathrm{H} 4$ and RNA polymerase II in the 2-cell mouse embryo. Development 1995; 121: 2949-2959. [Medline]

44. Wiekowski M, Miranda M, DePamphilis ML. Regulation of gene expression in preimplantation mouse embryos: effects of the zygotic clock and the first mitosis on promoter and enhancer activities. Dev Biol 1991; 147: 403-414. [Medline] [CrossRef]

45. Wiekowski M, Miranda M, DePamphilis ML. Requirements for promoter activity in mouse oocytes and embryos distinguish paternal pronuclei from maternal and zygotic nuclei. Dev Biol 1993; 159: 366-378. [Medline] [CrossRef]

46. Henery CC, Miranda M, Wiekowski M, Wilmut I, DePamphilis ML. Repression of gene expression at the beginning of mouse development. Dev Biol 1995; 169: 448-460. [Medline] [CrossRef] 